\title{
Early and Mid-term Outcome of CABG Surgery in Diabetic and Non-diabetic Patients in a Tertiary Care Hospital in Bangladesh
}

\author{
Rahman $\mathrm{MM}^{1^{*}}$, Karim $\mathrm{MR}^{2}$, Rahman $\mathrm{MH}^{3}$, Siraj $\mathrm{M}^{1}$, Uddin $\mathrm{J}^{1}$, Amin $\mathrm{MN}^{4}$, Rashid $\mathrm{MA}^{2}$ \\ ${ }^{I}$ Department of Cardiac Surgery, Ibrahim Cardiac Hospital \& Research Institute, Dhaka, Bangladesh; \\ ${ }^{2}$ Department of Cardiology, Ibrahim Cardiac Hospital \& Research Institute, Dhaka, Bangladesh; \\ ${ }^{3}$ Department of Cardiac Anesthesiology, Ibrahim Cardiac Hospital \& Research Institute, Dhaka, \\ Bangladesh; ${ }^{4}$ Ibrahim Cardiac Medical Journal, Ibrahim Cardiac Hospital \& Research Institute, \\ Dhaka, Bangladesh;
}

\begin{abstract}
Background: Previous trials showed that diabetic patients had worse in-hospital and long term outcome after coronary artery bypass grafting (CABG) than non diabetic ones. However, the majority of such studies was carried out in western countries and limited information is available for the Asian population.
\end{abstract}

Objective: The present study was intended to determine the impact of diabetes on early and mid-term outcome among patients undergoing CABG surgery in a tertiary care hospital in Bangladesh.

Methods: This study was performed at Ibrahim Cardiac Hospital \& Research Institute, Dhaka, Bangladesh, from January to June 2014. Based on enrollment criteria, 202 patients (115 diabeticsand 87 non-diabetics) were enrolled and evaluated for their early outcome (within 30 days of operation) and midterm (after 30 days postoperatively). Patients with known diabetes or preoperative fasting blood sugar $\geq 6.4 \mathrm{mmol} / \mathrm{L}$ or random blood sugar $\geq 11.1 \mathrm{mmol} / \mathrm{L}$ were considered as diabetics. The outcome measures were ICU stay, reopening for bleeding, atrial fibrilation, cardiac arrest, total hospital stay, left ventricular ejection fraction and mortality.

Results: Diabetic patients in this study had higher prevalence of hypertension, hyperlipidaemia, and renal failure. The diabetic and the non diabetic groups received a mean number of grafts of $3.2 \pm 1.06$ and $2.81 \pm 1.21$, respectively, Postoperative mortality in diabetic and non-diabetic patients at early and mid-term were not significantly different in univariate analysis $(4.3 \%$ vs. $2.3 \%, p=0.352)$ and $(2.6 \%$ vs. $2.3 \%, p=$ $0.630)$ respectively. The mean intensive care unit (ICU) stay in diabetic and non-diabetic were same (3.5days) but total hospital stay was significantly higher in the former group (one day or more). Re-opening for bleeding, atrial fibrilation and cardiac arrest in ICU were found higher in DM than those in non-DM group (28.7\%vs. $20.7 \%, 10.4 \%$ vs. $8 \%$ and $4.2 \%$ vs. $1.1 \%$ respectively).

Conclusion: Although the mortality rate of diabetic patients following CABG surgery was in significantly higher than their non-diabetic counterparts. Morbidity was also a bit higher. Strict perioperative glyacemic control could reduce morbidity and mortality in diabetic patients undergoing CABG.

Keywords: Coronary artery bypass graft, Diabetes mellitus, Early and mid term outcome, Non diabetic

\section{Introduction}

Diabetes mellitus (DM) is a well-known risk factor for coronary artery disease and cardiovascular death. ${ }^{1}$ The prevalence of DM is steadily increasing and by 2025 it will be about 300 million (5.4\% of the world population). ${ }^{2}$

The point prevalence of diabetes in patients undergoing coronary artery bypass graft (CABG) surgery ranges from $12-38 \% \cdot{ }^{3-5}$ Diabetes has been associated with increased morbidity and mortality in association with $\mathrm{CABG}$ and is a strong predictor for risk of deathand mediastinitis. ${ }^{6-8}$ Diabetic patients more often suffer from postoperative stroke and their average stay at hospital is longer than that of the non-

Correspondence: Md. Mazibur Rahman, Department of Cardiac Surgery, Ibrahim Cardiac Hospital \& Research Institute, Shahbagh, Dhaka, Bangladesh; e-mail: drmuzib2009@yahoo.com; ORCID: 0000-0003-0918-1154 diabetics. Despite DM being an established risk factor for significant morbidity and mortality after CABG surgery, revascularization in diabetic patients appears to have long-term benefit compared to PCI. ${ }^{9-14}$ In addition, the prevalence of DM in Asian CABG patients were consistently higher than that in Caucasians. ${ }^{9,15-17}$ Diabetes is a risk factor for early hospital death in Japanese patients, although it did not affect their long term survival. ${ }^{16}$

There are conflicting data about the early and midterm results of CABG in diabetic patients and remains a subject of debate, while some studies reported a significant negative impact of DM, others have suggested a better outcome. , $^{4,15,16,18-21}$ However, the majority of such study were carried out in western countries and limited information is available for the Asian population. ${ }^{3,9,11,15}$ There is paucity of data about the Bangladeshi people. In 
Ibrahim Cardiac Hospital and Research Institute, it was planned to evaluate the early and midterm outcome of DM patients undergoing CABG. The result of this study will be helpful to formulate treatment guideline for both DM and non-DM patients undergoing $\mathrm{CABG}$ in particular $\mathrm{CABG}$ patients having DM.

\section{Materials and Methods}

This prospective study commenced on obtaining approval from the Institutional Review Board of the Ibrahim Cardiac Hospital \& Research Institute (ICHRI). A total of 202 consecutive patients who underwent isolated CABG from January to June 2014 were included. Of them, 115 were diabetics and 87 were non-diabetics. All patients undergoing elective CABG surgery regardless of their age, sex, diabetes status or its type, duration and use of anti-diabetic agents were included in the study. However, patients who underwent simultaneous CABG with valvular heart surgery either replacement or repair, $\mathrm{CABG}$ with $\mathrm{ICR}$ in congenital heart disease, gestational diabetic patients, small $(\leq 1$ $\mathrm{mm}$ diameter) target vessels and emergency CABG surgery were excluded from the study.

Data were collected on variables of interest like age, sex, family history, body mass index (BMI), history of smoking, dyslipidemia (defined as total cholesterol of $>200 \mathrm{mg} / \mathrm{dl}$ or a history of elevated serum total cholesterol during the previous 6 months resulting in lipid lowering agent prescription), hypertension, old myocardial infarction, cerebrovascular disease, peripheral vascular disease, left main coronary artery disease, preoperative renal failure, and left ventricular ejection fraction. The operative data such as use of cardiopulmonary bypass, aortic cross clamp time, and use of intra aortic balloon pump were also gathered. The postoperative outcome data were collected on early mortality (defined as death during their stay in the hospital including operating room death and the deaths occurring within 30 days postoperatively), mid-term mortality (death occurring after 30 days of CABG but within five years after operation),stroke [(defined as a central neurologic deficit persisting more than 72 hours (i.e., extremity weakness or loss of motion, loss of consciousness, loss of speech, field cuts)], transient ischemic attack (TIA) (loss of neurological function that was abrupt in onset but with complete return of function within 24 hours), coma (a new postoperative coma that persisted for at least 24 hours secondary to anoxic/ischemic and/or metabolic encephalopathy, thromboembolic event or cerebral bleed), postoperative renal failure (acute or worsening renal failure resulting in one or more of the following: a) increase of serum creatinine to $>2.0 \mathrm{mg} / \mathrm{dl}$ and 2-times the baseline creatinine level b)a new requirement for dialysis), c) prolonged intubation time (the patient was under pulmonary ventilator for $>24$ hours), superficial/ deep sternal wound infection, reopening for mediastinal bleeding, cardiac arrest (the patient had an acute cardiac arrest documented by one of the following: a) ventricular fibrillation, b) rapid ventricular tachycardia with hemodynamic instability, and c) asystole), atrial fibrillation (AF) presented within two weeks of the procedure and cardiac death (defined as any mortality related to heart disease or sudden death and non-cardiac death related to other causes).

Data were collected by interview of the patients and physical examination using a pre-tested questionnaire and standardised measurement protocols. Interview was done to elicit information on demographic characteristics, tobacco use, physical activity and diagnosis and treatment history for hypercholestaerolemia, diabetes and hypertension. The following physical and biochemical examinations were performed: measurements of height and weight (to calculate BMI), blood pressure, resting pulse rate, blood glucose level and level of cholesterol. For assessing diabetes status- each participant was asked whether they had diabetes but in case, if the participant did not know about his/her diabetes status, he/she was tested for blood glucose level. Continuous variables were presented as mean \pm SD (standard deviation), while categorical variables were expressed as absolute frequencies and percentages. Continuous variables were compared between the two study groups (diabetic and nondiabetic) using Student's t-test and categorical variables were compared using Chi-square or Fisher's exact test, as required. For statistical analysis, the statistical software SPSS version 16.0 for windows was used. Level of significance was set 0.05 and $p<0.05$ was considered significant.

\section{Results}

Out of 202 patients available for the study, $115(56.9 \%)$ were diabetic and the remaining $87(43.1 \%)$ were non-diabetic. Majority of the patients in either group was male. The mean ages of the diabetic and non-diabetic patients were almost similar (53.4 \pm 8.36 vs. $52.8 \pm 9.6)$ (table I). 
Table I: Demographic data of CABG surgery of both DM and nonDM patient

\begin{tabular}{lcc}
\hline \multirow{2}{*}{$\begin{array}{l}\text { Demographic } \\
\text { characteristics }\end{array}$} & \multicolumn{2}{c}{ Group } \\
\cline { 2 - 3 } Age $^{\#}$ & DM (n=115) & Non-DM (n=87) \\
Gender* & $53.44 \pm 8.36$ & $52.79 \pm 9.6$ \\
Male & $98(85.2)$ & $80(92.0)$ \\
Female & $17(14.8)$ & $7(8.0)$ \\
Occupation* & & \\
Business & $48(41.7)$ & $57(65.5)$ \\
Service holder & $52(45.2)$ & $26(29.9)$ \\
House wife & $15(13.0)$ & $2(2.3)$ \\
\hline
\end{tabular}

*Data were analysed using Chi-square test;figures in the parentheses denote corresponding percentage

\#Data were analysed using Unpaired t-test and were presented asmean $\pm \mathrm{SD}$.

Patients' preoperative characteristics and risk factors distribution were assessed(table II). Left ventricular ejection fraction (LVEF) was observed to be significantly higher $(52.4 \%)$ in the DM group than that in the non-DM group $(49.5 \%)(p=0.013)$. The mean $\mathrm{HbAl} \mathrm{c}$ was much higher in the diabetic patients (8.4\%) compared to their non-diabetic counterparts $(6.3 \%)(p<0.001)$. All other characteristics and risk factors were almost identically distributed between groups ( $p>0.05$ in each case).

Table II: Baseline characteristic of DM and non-DM patients

\begin{tabular}{|c|c|c|c|}
\hline \multirow{2}{*}{$\begin{array}{l}\text { Baseline } \\
\text { characteristic }\end{array}$} & \multicolumn{2}{|c|}{ Group } & \multirow[b]{2}{*}{$p$} \\
\hline & $\begin{array}{l}\begin{array}{l}\text { DM } \\
(n=115)\end{array} \\
\end{array}$ & $\begin{array}{l}\begin{array}{l}\text { Non-DM } \\
(\mathrm{n}=87)\end{array} \\
\end{array}$ & \\
\hline $\mathrm{BMI}^{\#}$ & $25.5 \pm 3.4$ & $25.5 \pm 2.8$ & 0.956 \\
\hline Smoker* & $84(73.0)$ & $58(66.7)$ & 0.111 \\
\hline Dyslipidemia* & 111(96.5) & $82(94.3)$ & 0.503 \\
\hline Hypertension* & $110(95.7)$ & $81(93.1)$ & 0.536 \\
\hline Renal Failure* & $15(13.5)$ & $6(6.9)$ & 0.166 \\
\hline $\begin{array}{l}\text { Left main } \\
\text { Lesion* }\end{array}$ & $26(22.6)$ & $22(25.3)$ & 0.739 \\
\hline LVEF" & $52.4 \pm 8.9$ & $49.5 \pm 7.2$ & 0.013 \\
\hline $\begin{array}{l}\text { Family History } \\
\text { of CAD* }\end{array}$ & $48(41.7)$ & $35(40.2)$ & 0.016 \\
\hline Euro Score ${ }^{\#}$ & $1.8 \pm 1.32$ & $1.9 \pm 1.49$ & 0.607 \\
\hline $\mathrm{HbA1} \mathrm{c}^{\#}$ & $8.40 \pm 1.5$ & $6.3 \pm 1.0$ & $<0.001$ \\
\hline
\end{tabular}

*Data were analysed using Chi-square test; figures in the parentheses denote corresponding percentage

\#Data were analysed using Unpaired t-test and were presented asmean $\pm \mathrm{SD}$.
Table III: Operative characteristics of both DM and non-DM

\begin{tabular}{lccc}
\hline $\begin{array}{l}\text { Operative } \\
\text { Characteristics }\end{array}$ & \multicolumn{2}{c}{ Groups } & \\
\cline { 2 - 3 } & $\begin{array}{c}\text { DM } \\
(\mathbf{n = 1 1 5})\end{array}$ & $\begin{array}{c}\text { Non-DM } \\
(\mathbf{n = 8 7})\end{array}$ & $\boldsymbol{p}$ \\
\hline IABP* & $10(8.7)$ & $4(4.6)$ & 0.256 \\
$\begin{array}{l}\text { Cross-clamp } \\
\text { time (minutes) }\end{array}$ & $50.9 \pm 19.2$ & $39.2 \pm 17.9$ & $<0.001$ \\
$\begin{array}{l}\text { CPB time } \\
\text { (minutes) }\end{array}$ & $104.4 \pm$ & $79.5 \pm 35.5$ & $<0.001$ \\
No. of grafts & 45.1 & & \\
\hline
\end{tabular}

*Data were analysed using Chi-square test; figures in the parentheses denote corresponding percentage

\#Data were analysed using Unpaired t-test and were presented asmean \pm SD.

The incidence of intra aortic balloon pump (IABP) insertion was considerably higher in the DM group than that in the non-DM group, although the difference was not significant $(p=0.256)$. Cardiopulmonary bypass (CPB) time and Cross Clamp Times (XCT) were significantly higher in diabetic than in non-diabetic patients $(p<0.001$ and $p<$ $0.001)$. The diabetic and the non-diabetic groups received a mean number of grafts of $>3$ and $<3$ respectively and the mean size of the grafted arteries were $(1.38 \pm 0.16 \mathrm{~mm}$ and $1.47 \pm 0.11 \mathrm{~mm}$ respectively) (table III).

Table IV: Postoperative outcomes in diabetic and non-diabetic patients

\begin{tabular}{lccc}
\hline \multicolumn{1}{c}{$\begin{array}{c}\text { Postoperative } \\
\text { outcomes }\end{array}$} & $\begin{array}{c}\text { DM } \\
\text { (n=115) }\end{array}$ & $\begin{array}{c}\text { Non-DM } \\
\text { (n=87) }\end{array}$ & $\boldsymbol{p}$ \\
\cline { 2 - 3 } & $5(4.3)$ & $2(2.3)$ & 0.542 \\
\hline $\begin{array}{l}\text { In-hospital } \\
\text { Mortality* }\end{array}$ & $3.8 \pm 1.1$ & $3.5 \pm 1.0$ & 0.338 \\
$\begin{array}{l}\text { ICU stay } \\
\text { Re-opening due } \\
\text { to bleeding* }\end{array}$ & $33(28.7)$ & $18(20.7)$ & 0.252 \\
$\begin{array}{l}\text { Atrial fibrillation } \\
\text { (AF)* }\end{array}$ & $12(10.4)$ & $7(8.0)$ & 0.633 \\
$\begin{array}{l}\text { Cardiac arrest in } \\
\text { ICU* }\end{array}$ & $4(4.2)$ & $1(1.1)$ & 0.371 \\
$\begin{array}{l}\text { Total hospital } \\
\text { stay }\end{array}$ & $8.1 \pm 1.6$ & $6.8 \pm 0.9$ & $<0.001$ \\
Echo LVEF & $52.4 \pm 8.9$ & $49.5 \pm 7.2$ & 0.013 \\
\hline
\end{tabular}

*Data were analysed using Chi-square test; figures in the parentheses denote corresponding percentage.

\#Data were analysed using Unpaired t-test and were presented asmean \pm SD. 


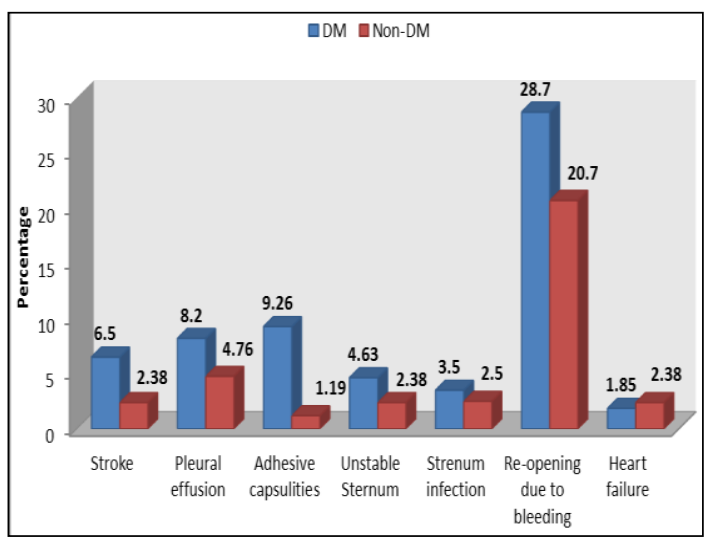

Figure 1: Compsarison of post-operative complications of DM and Non-DM patients

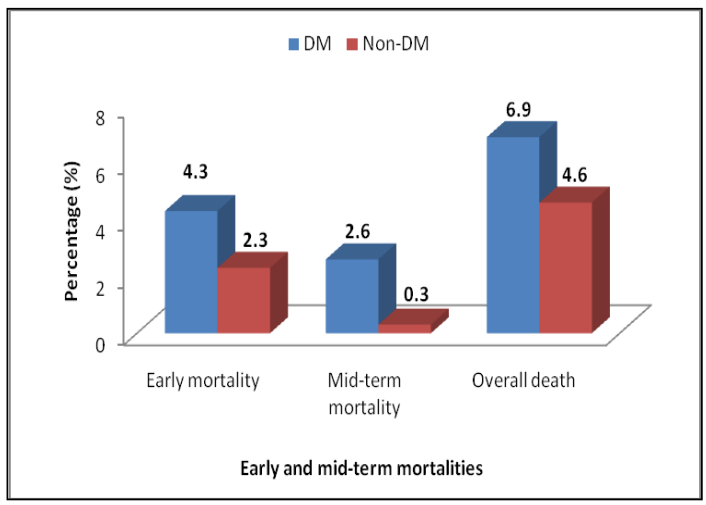

Figure 2: Comparison of early and mid-term mortalities of DM and Non-DM patients

Postoperative outcomes show that early mortality (30-day mortality) was more frequent in diabetics than in non-diabetics, though the difference was not significant ( $4.3 \%$ vs. $2.3 \%, p=0.542)$. The ICU stays in diabetic and non-diabetics were almost identical $(p=0.338)$, but total hospital stay was significantly higher in the former group than that in the latter group. Reopening due to bleeding, atrial fibrilation and cardiac arrest in ICU were found higher in DM than those in non-DM but the differences did not turn to significant $(p=0.252, p=0.633$ and $p=0.371$ respectively) (table IV). No significant difference was observed between DM and non-DM patients in terms of incidence of stroke $(6.50 \%$ vs. $2.38 \%, p=0.196)$, pleural effusion $(7.41 \%$ vs. $4.76 \%, p=0.354)$, adhesive capsulities ( $9.26 \%$ vs. $1.19 \%, p=0.019$ ), unstable sternum $(4.36 \%$ vs. $2.38 \%, p=0.245)$, sternum infection (3.5\% vs. $2.5 \%, p=0.480)$ and reopening for bleeding ( $28.7 \%$ vs. $20.7 \%, p=0.195$ ) respectively. All were more prevalent in diabetic patients than non-diabetic ones except heart failure ( $1.85 \%$ vs. $2.38 \%, p=0.777$ ) (figure 1 ). In the first month following CABG 7(3.5\%) patients died. Cardiac mortality was the major cause of death in this period and constituted $85.7 \%$ of all deaths. However, there was no significant difference between the study groups in terms of early or mid-term mortality ( $p=$ 0.352 and $p=0.630$ ). Overall survival after surgery and during follow up period was lower in diabetics ( $p=0.483)$.

\section{Discussion}

Ischaemic heart disease is not only more prevalent in diabetic patients compared to non-diabetic but it tends to be more extensive, rapidly progressive involving multiple vessels. The prevalence of diabetes is rising owing to an increasingly aged and obese population..$^{22}$ Arteriosclerosis is responsible for $80 \%$ of deaths in patients with DM. ${ }^{17}$ The adverse impact of DM on the outcome of CABG patients is related to its atherosclerotic, proinflammatory, and pro-thrombotic effects. ${ }^{1}$ In a previous study reported by Thourani et al. $^{7}$ the mortality was significantly higher among the diabetics $(3.9 \%)$ compared to the non-diabetic population $(1.6 \%)$. The North American multicenter Registry data of Carson et alhaving 146,786 patients who underwent CABG surgery in 1997 reported a 30-day mortality of $3.7 \%$ in diabetic patients compared to $2.7 \%$ in nondiabetics. ${ }^{15}$ However, according to this study and several other recent reports, early mortality in patients with diabetes was not significantly different from those without diabetes. Szabo et al (published in 2002), Rajakaruna et al (in 2006), and Filsoufi et al (in 2007)., , $^{3,19,21}$ reported mortality rates of $2.6 \%, 2.2 \%, 1.0 \%$ respectively in diabetic patients and did not isolate diabetes as an independent predictor of early mortality.

It is now clear that the impact of DM on early mortality has changed over time. According to the Society of Cardiothoracic Surgeons of Great Britain and Ireland, in 1997, diabetic patients were twice as likely to die after CABG compared to non-diabetics (5.9\% vs. $3.0 \%$ ) but by 2001 there have been a significant reduction in the operative mortality $(2.9 \%$ vs. $2.2 \%)$, practically eliminating diabetes as an additional risk. Better knowledge of the pathophysiology and improved perioperative control of the disease may have contributed to this evolution. 
The diabetic and the non diabetic groups received a mean number of grafts of $>3$ and $<3$ respectively. The average hospital stay in diabetic group was one and a half day more than that in non-diabetic group. Diabetic patients also have higher in-hospital morbidity which might be due to adverse consequences of hyperglycemia. Uncontrolled hyperglycaemia may be associated with dehydration and electrolyte disturbances. ${ }^{15}$ Impaired function ofneutrophil leucocytes is the other adverse effects of hyperglycaemia which leads to higher rate of postoperative infections and impaired wound healingand also contribute to increased platelet activity, alteration in coagulation physiology, fibrinolysis, lipid metabolism as well as endothelial function. ${ }^{22-30}$ Consistent with the findings of our study, Zerr et al who showed that using a continuous insulin infusion protocol in perioperative period to control blood glucose results in lower rate of in-hospital mortality and morbidity. ${ }^{31}$ It has also been shown that lowering mean blood glucose level to less than $200 \mathrm{mg} / \mathrm{dL}$ in the immediate post-operative period results in a reduced incidence of deep wound infection in diabetic patients. ${ }^{32}$ On the contrary, Carson et $\mathrm{l}^{15}$ demonstrated that the mortality effect was greatest among diabetics treated with insulin $(\mathrm{OR}=1.39 ; 95 \% \mathrm{CI}: 1.27$ to 1.52) and less pronounced, but still significant, in patients treated with oral hypoglycaemic agents $(\mathrm{OR}=1.13 ; 95 \% \mathrm{CI}: 1.04$ to 1.23$) .{ }^{15}$ Importantly, although death was attributable to cardiac causes (which generally includes ischaemiadue to graft failure, left ventricular failure and dysrythmia) in approximately $2 / 3^{\text {rd }}$ of all patients, neurologic events led to $9.64 \%$ of non DM perioperative death. This suggest that the excess short term mortality in diabetics undergoing $\mathrm{CABG}$ is largely due to increased non cardiac mortality including hypertension, chronic renal failure, cerebrovascular disease (neurologic), peripheral vascular disease, infections and perhaps other causes. ${ }^{9,11,15,20}$ Whether careful vigilance and awareness of these issues in the perioperative period can reduce mortality and morbidity in diabetics is not clear. In this setting, postoperative glycaemic control was strictly monitored and managed and probably for that reason the mortality and morbidity in diabetics were not significantly higher than those in non-DM patients.

An association between diabetes and unstable sternum has been reported in previous studies. ${ }^{3,15}$ In this study, it was to be found higher incidence of unstable sternum in diabetic patients as compared to non-diabetics. It was also found higher incidence of postoperative stroke among diabetics similar to Herlitz et al. ${ }^{3}$ This finding differs from Kubal et alwho found no association between DM and postoperative stroke. ${ }^{33}$ The present study also found a significant difference in the occurrence of cardiac arrest in ICU after CABG in diabetic patients. The study also showed no significant increase in the incidence of postoperative renal failure in diabetic patients and this finding differs from other studies. ${ }^{4,21,33}$

Yamamoto et al found that using left internal mammary artery graft results in similar survival rate between diabetic and non diabetic patients. ${ }^{16} \mathrm{It}$ was to be thought that different baseline characteristics of patients enrolled in these studies may be an important factor affecting short term results. Enrolling patients with diffuse distal coronary artery disease and poor run-off could increase postoperative infarction and mortality, while excluding this group of patients will result in better short term outcome. As described above there is less controversy about poor long term outcome of CABG in diabetic patients. Different pattern of coronary artery involvement in diabetic patients like diffuse and more distal distribution of atherosclerosis are important factors affecting the rate of subsequent ischaemic events and recurrent angina or infarction. ${ }^{12,32}$ Schwartz et al showed that grafted vessels in diabetic patients were smaller than non-diabetics with more diffuse involvement, which bear consistency with the findings of our study. ${ }^{17}$ Prior studies that evaluated postoperative complications largely focused on individual diseases and were too small to detect differences in morbidity outcomes. ${ }^{3,7,22,23}$ Diabetic patients in our study had higher prevalence of renal failure but had slightly higher ejection fraction than non-diabetics.

The possible explanations for the relation between DM and increased mortality and complications after 
$\mathrm{CAB}$ Gare that patients with DM usually have more advanced and diffuse cardiac disease at the time of surgery. It is considered that the metabolic abnormalities associated with hyperglycemia are responsible for some of the increased mortality and morbidity. Hyperglycemia interferes with the function of polymorphonuclear leukocytes predisposing to infection and may impair wound healing. ${ }^{22-27}$ Some studies suggest a relation between improved glucose control in the peri-operative period and lower rates of wound infection and dehiscence. ${ }^{31,34,35}$ Hyperglycaemia could also contribute to increased platelet activity and disordered coagulation and fibrinolytic functionas well as abnormalities in lipid metabolism. ${ }^{29}$ Hyperglycaemia also affects endothelial function. ${ }^{30}$ Dehydration and electrolyte disturbances as a result of uncontrolled hyper glycaemia could also contribute to the outcome. Free fatty acids levels are elevated after major surgery and could suppress cardiac function increasing myocardial oxygen demand and may be arrhythmogenic. ${ }^{36-39}$

This study has several limitations that need to be clearly addressed. While here it was controlled for many known risk factors previously demonstrated to be associated with mortality (demographic characteristics, preoperative risk factors including most common co-morbidities, preoperative cardiac status, preoperative medications, preoperative hemodynamic and catheterization data, and operative information), it is still possible that there is residual confounding risk factors which might have contributed to increased mortality. Secondly, postoperative complications of these CABG patients were not detailed, as they have been reported in many previous papers. ${ }^{15,17,40}$ Thirdly, our diabetic patients were not feasible to be divided into insulin dependent and non-insulin-dependent subgroups, despite in this study attempt to retrieve such data from the patient's clinical reports. Some studies have suggested that insulin-dependent diabetic patients undergoing $\mathrm{CABG}$ are at higher risk than non- insulin-dependent patients. ${ }^{19,34,35}$

\section{Conclusion}

The mortality rate of diabetic patients following CABG surgery was somewhat higher than their non-diabetic counterparts. Postoperative complications were also a bit higher. But none of the complications (except adhesive capsulitis) was significantly higher in diabetic cohort. Strict perioperative glycaemic control might have reduced mortality and morbidity in diabetic patients undergoing CABG. Results of this study, have important implications that diabetic patients undergoing $\mathrm{CABG}$ are at modest risk of death or sufferings compared to non-diabetics. Large-scale, multi-centre study is recommended to validate the findings of the present study.

\section{Conflict of interest: No conflict of interest}

\section{Acknowledgements}

The study was funded by Bangladesh Medical Research Council (BMRC). We are thank feel the patients who participated in this study and the staff members who adhered with this study. We would like to express our appreciation towards the ICHRI authority for their administrative support.

\section{References}

1. Raman M, Nesto RW. Heart disease in diabetes mellitus. Endocrinol metabol Clin North AM.1996; 25:425-38.

2. Monteiro P, Goncalves L, Providencia LA. Diabetes and cardiovascular disease: the road to cardio protection. Heart. 2005; 91:1621-25.

3. Herlitz J, Wognsen GB, Karlson BW, Sjöland H, Karlsson T, Caidahl K et al. Mortality, mode of death and risk indicators for death during 5 years after coronary artery bypass grafting among patients with and without a history of diabetes mellitus. Coronary Artery Diseases.2000; 11:339-46.

4. Szabo Z, Hakanson E, Svedjeholm R. Early postoperative outcome and medium-term survival in 540 diabetic and 2239 non-diabetic patients undergoing coronary artery bypass grafting. Ann Thoracic Surgery. 2002; 74:712-19.

5. Barsness GW, Peterson ED, Ohman EM, Nelson CL, De Long ER, Reves JG, et al. Relationship between diabetes mellitus and long-term survival after coronary bypass and angioplasty. Circulation. 1997; 96:2551-56.

6. Clough RA, Leavitt BJ, Morton JR, Plume SK, Hernandez F, Nugent $W$ et al. The effect of comorbid illness on mortality outcomes in cardiac surgery. Arch Surgery. 2002; 137:428-33

7. Thourani VH, Weintraub WS, Stein B,Gebhart SS, Craver JM, Jones EL et al. Influence of diabetes mellitus on early and late outcome after coronary artery bypass grafting. Ann Thorac Surg. 1999; 67:1045-52. 
8. Braxton JH, Marrin CA, McGrath PD, Ross CS, Morton JR, Norotsky $M$ et al. Mediastinitis and long-term survival after coronary artery bypass graft surgery. Northern New England Cardiovascular Disease Study Group. Ann Thoracic Surgery. 2000; 70: 2004-07.

9. Wood SE, Smith JM, Sohail S, Sarah A, Engle A. The influence of type 2 diabetes mellitus in patients undergoing coronary artery bypass graft surgery: and 8-year prospective cohort study.Chest 2004;126:1789-95.

10. Niles NW, McGrath PD, Malenka D, Quinton H, Wennberg D, Shubrooks SJ et al. Survival of patients with diabetes and multivessel coronary artery disease after surgical or percutaneous coronary revascularization: results of a large regional prospective study. Northern New England Cardiovascular Disease Study Group. J Am Coll Cardiol. 2001;37:1008-15.

11. Leavitt BJ, Sheppard L, Maloney C, Clough RA, Braxton JH, Charlesworth DC et al. Effect of diabetes and associated conditions on long-term survival after coronary artery bypass graft surgery. Circulation 2004;110(11Suppl1):II 41-44.

12. Kip KE, Alderman EL, Bourassa MG, Brooks MM, Schwartz L, Holmes DR Jret al. Differential influence of diabetes mellituson increased jeopardized myocardium after initial angioplasty or bypass surgery: bypass angioplasty revascularization investigation. Circulation. 2002;105:1914-20.

13. Detre KM, Guo P, Holubkov R Califf RM, Sopko $\mathrm{G}$, Bach $\mathrm{R}$, et al. Coronary revascularization in diabetic patients: a comparison of the randomized and observational components of the Bypass Angioplasty Revascularization Investigation (BARI). Circulation. 1999;99:633-40.

14. Comparison of coronary bypass surgery with angioplasty in patients with multivessel disease. The Bypass Angioplasty Revascularization Investigation (BARI) Investigators. N Engl J Med. 1996;335:217-25.

15. Carson JL, Scholz PM, Chen AY, Peterson ED, Gold J, Schneider SH. Diabetes mellitus increases short term mortality and morbidity in patients undergoing coronary artery bypass graft surgery.J Am Coll Cardiol. 2002;40:418-23.

16. Yamamoto T, Hosoda Y, Takazawa K, HayashiI, Miyagawa H, Sasaguri S. Isdiabetes mellitus a major risk factor in coronary artery bypass grafting? Theinfluence of internal thoracic artery grafting on late survival in diabetic patients. Jpn J Thorac Cardiovasc Surg.2000;48:344-52.

17. Schwartz L, Kip KE, Frye RL, Alderman EL, Schaff HV, Detre KM et al. Bypass Angioplasty Revascularization Investigation. Coronary bypass graft patency in patients with diabetes in the Bypass, Angioplasty Revascularization Investigation (BARI). Circulation. 2002; 106:2652-58.

18. Filsoufi F, Rahmanian PB, Castillo JG, Mechanick JI, Sharma SK, Adams DH. Diabetes is not a risk factor for hospital mortality following contemporary coronary artery bypass grafting. Interact CardiovascThorac Surg. 2007; 6:753-58.

19. Luciani N, Nasso G, Gaudino M, Abbate A, Glieca $\mathrm{F}$, Alessandrini $\mathrm{F}$ et al. The effectof diabetes mellitus on patients undergoing coronary surgery: A risk-adjusted analysis. J Thorac Cardiovasc Surg. 2006; 132:802-10.

20. Au WK, Lam KT, Cheng LC, Chiu SW. Impact of diabetes on early and mid-term survival after coronary artery bypass graft surgery the Hong Kong Chinese population. Hong Kong Med J. $2009 ; 15: 173-78$.

21. Rajakaruna C, Rogers CA, Suranimala C,Angelini $\mathrm{GD}$, Ascione R. The effect of diabetes mellitus on patients undergoing coronary surgery; a risk adjusted analysis. J Thorac Cardiovasc Surg. 2006; 132:802-10.

22. Garber AJ, Vascular disease and lipid in diabetes. Med Clin NorthAm. 1998; 82:931-48.

23. Salomon NW, Page US, Okies JE, Stephens J, Krause AH, Bigelow JC. Diabetes mellitus And coronary artery bypass: short-term risk and longterm prognosis. J Thoracic Cardiovascular Surgery. $1983 ; 85: 264-71$.

24. Clement R, Rousou JA, Engelman RM, Breyer RH. Perioperative morbidity in diabetics requiring coronary artery bypass surgery. Ann Thorac Surg. 1988; 46:321-23.

25. Shuhaiber H, Chugh $\mathrm{T}$, Portoian-Shuhaiber $\mathrm{S}$, Ghosh D. Wound infection in cardiac surgery. J Cardiovascular Surgery (Torino). 1987;28:139-42.

26. Farrington M, Webster M, Fenn A, Phillips I. Study of cardiothoracic wound infection at St. Thomas' hospital. Br J Surgery. 1985; 72:759-62.

27. Bitkover CY, Gardlund B. Mediastinitis after cardiovascular operations: a case-control study of risk factors (see comments). Ann Thoracic Surgery. 1998; 65:36-40.

28. Ryan T, McCarthy JF, Rady MY,Serkey J, Gordon $\mathrm{S}$, Starr NJ et al. Early bloodstream infection after cardiopulmonary bypass: frequency rate, risk factors, and implications. Crit Care Med. 1997; 25:2009-14

29. Jain SK, Nagi DK, Slavin BM, Lumb PJ, Yudkin JS. Insulin therapy in type 2 diabetic subjects suppresses plasminogen activator inhibitor (PAI-1) activity and proinsulin- like molecules independently of glycaemic control. Diabetes Med 1993; 10:27-32. 
30. Williams SB, Goldfine AB, Timimi FK, Ting HH, Roddy MA, Simonson DCet al.Acute hyperglycaemia attenuates endothelial dependent vasodilation in humans in vivo. Circulation.1998; 97:1695-701.

31. Zerr KJ, Furnary AP, Shuhaiber H, Chugh T, Portoian-Shuhaiber S, Ghosh D. Wound infection in cardiac surgery. J Cardiovascular Surgery (Torino). 1987; 28:139-42.

32. Cariou B, Bonnevie L, Mayaudon H, Dupuy O, Ceccaldi B, Bauduceau B. Angio graphic characteristics of coronary artery disease in diabetic patients compared with matched nondiabetic subjects. Diabetes NutrMetab. 2000; 13:134-41.

33. Kubal CH, Srinivasan AK, Grayson AD, Farbi BM, Chairimers JA.Effects of risk adjusted diabetes on mortality and morbidity after coronary artery bypass surgery. Ann Thorac Surg. 2005; 79:1570-76.

34. Pomposelli JJ, Baxter JK III, Babineau TJ, Pomfret EA, Driscoll DF, Forse RA, et al. Early postoperative glucose control predicts nosocomial infection rate in diabetic patients. J Parenter Enteral Nutr.1998; 22:77-81.
35. Trick WE, Scheckler WE, Tokars JI, Jones KC, Rappen MI, Smith EM, et al. Modified risk factors associated with deep sternal site infection after coronary artery bypass grafting. J Thorac Cardiovasc Surg. 2000; 119:108-14.

36. Opie LH, Tansey M, Kennelly BM. Proposed metabolic vicious circle in patients with large myocardial infarcts and high plasma-free-fatty acid concentrations. Lancet. 1977; 2:890-92.

37. Mjos OD. Effect of free fatty acids on myocardial function and oxygen consumption in intact dogs. J Clin Invest. 1971; 50:1386-89.

38. Henderson AH, Most AS, Parmley WW, Gorlin R, Sonnenblick EH. Depression of myocardial contractility in rats by free fatty acids during hypoxia. Circ Res. 1970; 26:439-49.

39. Kurien VA, Yates PA, Oliver MF. The role of free fatty acids in the production of ventricular arrhythmias after acute coronary artery occlusion. Eur J Clin Invest. 1971; 1:225-41.

40. Kannel WB, Mc Gee DL. Diabetes and cardiovascular risk factors: the Framingham Study. Circulation. 1979; 59:8-13. 